\title{
Evaluation of parallel endplate osteotomy for severe rigid spinal deformities: a retrospective analysis of 36 cases with a minimum 2-year follow-up
}

\author{
Hang Liao ${ }^{\dagger}$, Peng Xie ${ }^{\dagger}$, Guizhou Zheng, Houguang Miao, Ningdao Li, Xuedong Li ${ }^{*}$ and Shixin Du*
}

\begin{abstract}
Background: To report on the technique and results of parallel endplate osteotomy (PEO) for severe rigid spinal deformity.

Methods: We retrospectively reviewed the clinical data of 36 patients with severe rigid spinal deformities who underwent PEO between July 2016 and December 2018 and who were followed up for at least 24 months.

Results: Following PEO, the kyphosis and scoliosis correction rates reached $77.4 \pm 14.0 \%$ and $72.2 \pm 18.2 \%$, respectively. The median intraoperative estimated blood loss was $1500 \mathrm{~mL}$ and the median operative time was $6.8 \mathrm{~h}$. The SF-36 scores of physical function, role-physical, bodily pain, general health, vitality, social function, role-emotional and mental health changed from $62 \pm 28,51 \pm 26,49 \pm 29,35 \pm 30,53 \pm 28,45 \pm 30,32 \pm 34$ and $54 \pm 18$ at baseline to $81 \pm 16,66 \pm 41,72 \pm 40,64 \pm 44,75 \pm 25,71 \pm 46,66 \pm 34$ and $76 \pm 28$ at 12 months postoperatively, $82 \pm 32,67 \pm 42$, $81 \pm 30,71 \pm 41,80 \pm 30,74 \pm 36,68 \pm 35$ and $85 \pm 33$ at 18 months postoperatively, and $86 \pm 21,83 \pm 33,88 \pm 26$, $79 \pm 39,86 \pm 36,86 \pm 48,80 \pm 47$ and $91 \pm 39$ at 24 months postoperatively, respectively.
\end{abstract}

Conclusions: PEO is an effective technique for successful correction of spinal deformities. At the two-year follow-up visit, all patients achieved better clinical results based on the SF-36 scores.

Keywords: Severe rigid spinal deformities, Parallel endplate osteotomy, Clinical outcomes, Spinal cord safety, Complications

\section{Background}

Severe, rigid angular kyphosis (Fig. 1A, B, C, D, E and F) and kyphoscoliosis (Fig. 1G, H, I, J, K and L) were considered insurmountable challenges for spinal correction surgery in the last century. Despite tremendous efforts by spine surgeons to find effective solutions, the corrective outcomes remain unsatisfactory, with a high incidence of

\footnotetext{
*Correspondence: DSX333126@126.com; xd1622@sina.com

${ }^{\dagger}$ Hang Liao and Peng Xie contributed to the work equllly and should be regarded as co-first authors.

Department of Orthopedics, The Third Affiliated Hospital (The Affiliated

Luohu Hospital) of Shenzhen University, Shenzhen 518000, PR, China
}

neurological complications and massive bleeding, posing major threats to various spinal correction procedures and technologies.

In severe spinal deformities, the Cobb angle of the main curve is more than $80-100^{\circ}$; in rigid spinal deformities, the flexibility of the main curve is less than 10-30 $\%$ [1]. Treatment is often accompanied by difficulties and complications. Many studies have identified a relationship between anterior thoracotomy and a further decline in the pulmonary function of the patients; therefore, surgeons prefer a posterior approach alone [2-4]. original author(s) and the source, provide a link to the Creative Commons licence, and indicate if changes were made. The images or other third party material in this article are included in the article's Creative Commons licence, unless indicated otherwise in a credit line to the material. If material is not included in the article's Creative Commons licence and your intended use is not permitted by statutory regulation or exceeds the permitted use, you will need to obtain permission directly from the copyright holder. To view a copy of this licence, visit http://creativecommons.org/licenses/by/4.0/. The Creative Commons Public Domain Dedication waiver (http://creativeco mmons.org/publicdomain/zero/1.0/) applies to the data made available in this article, unless otherwise stated in a credit line to the data. 


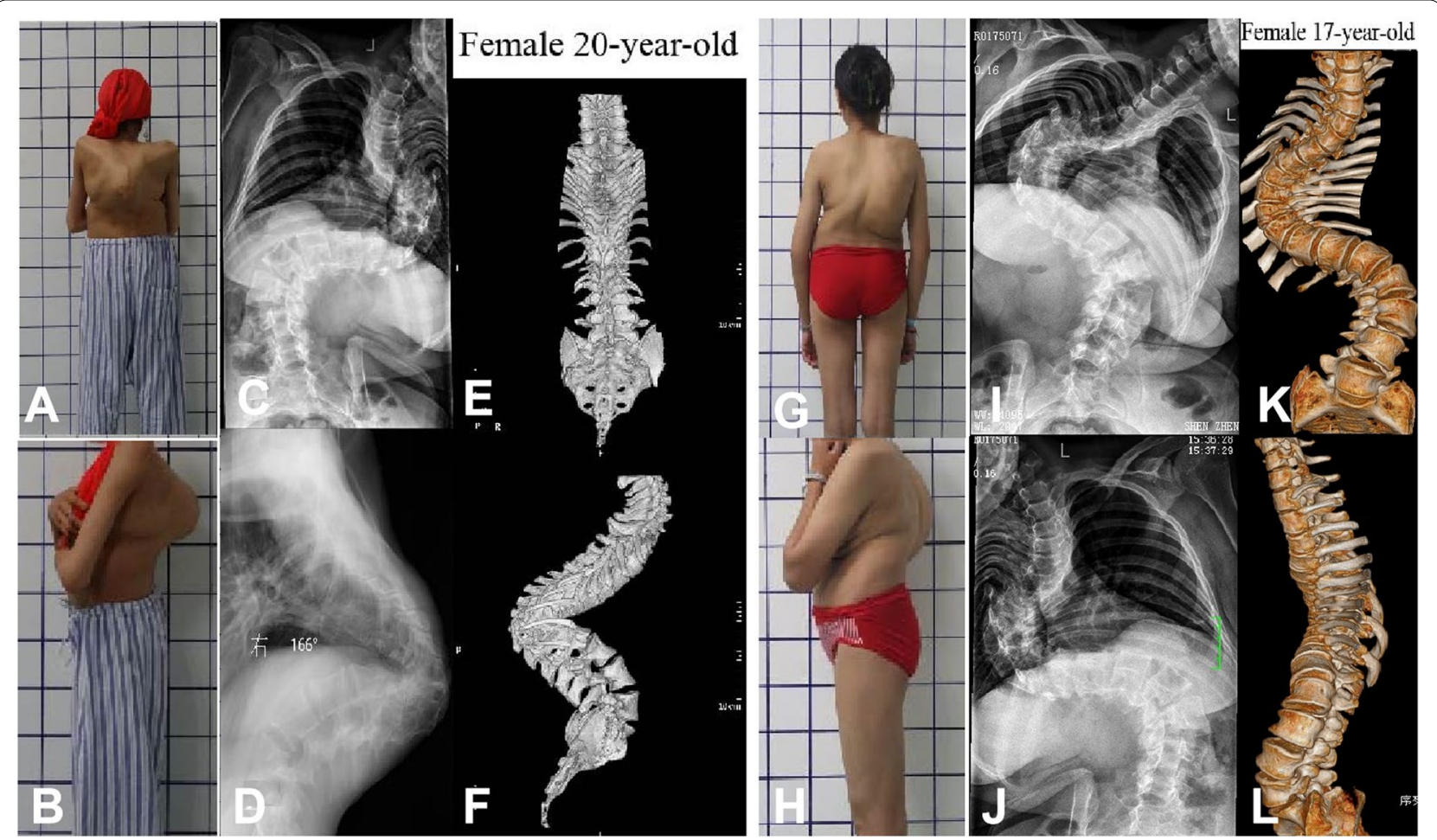

Fig. 1 Female, 22 years old, severe angular kyphosis. A, B, C, D, E and $\mathbf{F}$ Preoperative diagnosis was kyphosis: Cobb angle $166^{\circ}$ by profile, $X$-ray after bending, three-dimensional CT. Female, 17 years old, $\mathbf{G}, \mathbf{H}, \mathbf{I}, \mathbf{J}, \mathbf{K}$ and $\mathbf{L}$ ) Preoperative diagnosis was kyphosis: Cobb $99^{\circ}$ and scoliosis Cobb $97^{\circ}$ by profile, $\mathrm{X}$-ray after bending, three-dimensional CT

Although different types of osteotomies have been described and widely used to address large, stiff scoliotic or kyphotic curves [5-11], it should be noted that abnormal pedicle development, including absence of pedicles, cause more difficulties in osteotomies. However, the Scoliosis Research Society Morbidity and Mortality Committee reported that the incidence of complications including neural and non-neural injury during Smith Peterson osteotomies (SPO), pedicular subtraction osteotomy (PSO) and vertebral column resection (VCR) was 28.1, 39.1 and $61.1 \%$, respectively [12, 13]. To overcome these adversities, the present study was undertaken to evaluate and report on the technique and outcomes of parallel endplate osteotomy (PEO) for severe rigid spinal deformities at a single tertiary care institution.

\section{Methods}

\section{Patients}

This retrospective study enrolled patients with severe rigid spinal deformities who underwent PEO between July 2016 and December 2018. Spinal deformities were diagnosed by human grid analysis, roentgenography after bending or traction, three dimensional (3D) computed tomography $(\mathrm{CT})$ and $3 \mathrm{D}$ printing models. The inclusion criteria were 1) a spinal scoliosis and kyphosis angle more than $80^{\circ}$;2) flexibility less than $25 \%$; 3) receipt of one-stage posterior-only PEO and correction surgery; 4 ) a minimum 2-year postoperative follow-up. We excluded patients with any neurological deficits including those with spinal cord or nerve root injury or other serious respiratory complications before surgery.

The study protocol was approved by the institutional review board of the authors' affiliated institution. No patient consent was required because of the retrospective nature of the study. Patient data were anonymized in the paper.

\section{Assessment of deformity}

Instrumentation levels were determined according to the Cobb angle and flexibility of the main curve. Severe rigid spinal deformities were defined as having curve angles more than $80^{\circ}$, with flexibility less than $25 \%$ by X-rays after bending or traction [14]. The site of osteotomy was usually chosen as the vertebra that contributed most to the deformity according to the apex of the deformity.

\section{Surgical technique}

All surgeries were performed as a single-stage procedure by a single surgeon (the corresponding author, SXD) 
through a posterior incision. The surgical procedure has been described in our previous paper [15].

The patient was placed in the prone position on the operating table, on chest rolls. A single midline posterior longitudinal incision was made to expose the area at the previously determined levels. Paraspinal muscles and all soft tissues were stripped subperiosteally from the bone laterally to the tips of the transverse processes. Then, the pleural and paravertebral vessels were bluntly dissected. An intraoperative radiograph with guide pins was obtained for accurate localization of the deformity and determination of the level and area for osteotomy. Pedicle screws were inserted in the cephalic and the caudal aspects of the vertebrae identified for resection using a free-hand technique at all levels planned prior to surgery. It should be noted that abnormal pedicle development, including absence of pedicles, causes more difficulties in establishing the screw trajectory, and that screw insertion is time consuming [16]. Usually, the spine is stabilized with a short-bent rod in situ adjacent to the resected area to avoid coronal and sagittal plane translation during the reduction maneuver. Complete laminectomy and facetectomy were performed to expose the spinal cord. In the thoracic spine, the rib heads were removed to allow complete resection of the lateral wall of the vertebral body and to allow untethered motion of the vertebral column. The spinal cord is usually located in the concave curve side, but occasionally located in the convex curve side. In the latter case, we need to be more careful to avoid causing neurological complications due to high tension of the spinal cord. For example, some patients have no dural sac in the spinal cord, and in other cases the spinal cord is as tight as a cord with the diameter of only one-third of a normal spinal cord. Any slight maneuver would cause action potentials to decline sharply by over $50 \%$, or even disappear. Timely identification and prompt intervention must be performed, including enlarging the resected area to reduce the tendency of the spinal cord abrupt turning.

The spinal nerves were carefully dissected and preserved, but if they obstructed the osteotomy, one level of spinal nerve roots of the thorax on the convex curve side was usually resected. For PEO, the pedicle of the vertebral arch, $4 / 5$ of the posterior vertebra, the bilateral walls of the vertebra and the posterior wall of the vertebra ( $5 \mathrm{~mm}$ to the endplate) (Fig. 2A-D) were carefully removed using an osteotome, curette, rongeur and ultrasonic osteotome. The apex area of PEO was planned in which the anterior $1 / 5$ of the vertebral body was preserved during osteotomy. Compression over the resected area and shortening of the spine were performed to reduce tension on the spinal cord (Fig. 2E and F). The PEO area had two situations: 1 ) a single vertebral osteotomy, if the angle of the curve was less than $100^{\circ}$ (Fig. 3A-C), and 2) a multiple vertebral osteotomy, if the angle of the curve greater than $100^{\circ}$ (Fig. 3D-I).

The osteotomy was performed carefully to avoid over-penetration of the anterior vertebral body cortex or anterior intervertebral disc, for the purpose of providing a hinge point to avoid coronal and sagittal plane translation, and also to prevent injury to the major vessels in front of the vertebral body. Then, we inserted another pre-contoured correction rodon on the convex side to exchange the rods, with $30^{\circ}$ per correction. It was important in this step to keep an adequate compression force on the concave rod while its adjunct screws on the cephalic side were slightly released until the concave rod and screws were tightened one by one. In situ rod bending on the concave side should never be performed because it is a very dangerous procedure to the naked spinal cord and applying too much torsion to the pedicle screws could easily cause screw loosening and rod bender to stick out and injure the spinal cord. Therefore, we did not use the bent bar in PEO. After repeated compression and shuttling the segmental transient rod, we finally placed the terminal fixation rods after the main correction was achieved. The temporary rods should be exchanged with new rods because their mechanical integrity may be impaired by bending. Then, segmental derotation, compression, and distraction on the secondary curves were performed to achieve final correction. During the entire correction procedure, the dural sac was closely observed to avoid migration in any direction, and tension of the spinal cord was assessed by observation and frequent palpation. Adequate and quick adjustments were needed to ensure that spinal cord tension does not exceed the initial state under distraction, and to prevent excessive kinking of the dural sac after spinal shortening. Kawahara et al. confirmed that the spine shortened within one-third of the height of the vertebrae did not lead to a functional change of the spinal cord [17], but we did not worry about the excessive ruga of the dural sac. Spinal stability is always carefully maintained by the pedicle screw-rod system to prevent sudden migration of the spinal cord due to unstable instrumentation. We placed the terminal fixation rods after the main correction was achieved. After completion of resection and deformity correction, we filled any residual gap with resected vertebral body bone morsels [18].

We monitored somatosensory-evoked potential (SEP) and motor-evoked potential (MEP) to effectively monitor the spinal cord and nerve roots under the supervision of an experienced neurophysiologic physician throughout the PEO procedure, and an additional wake-up test was performed after completion of the correction step at the end of the surgery assess to the neurological status. 

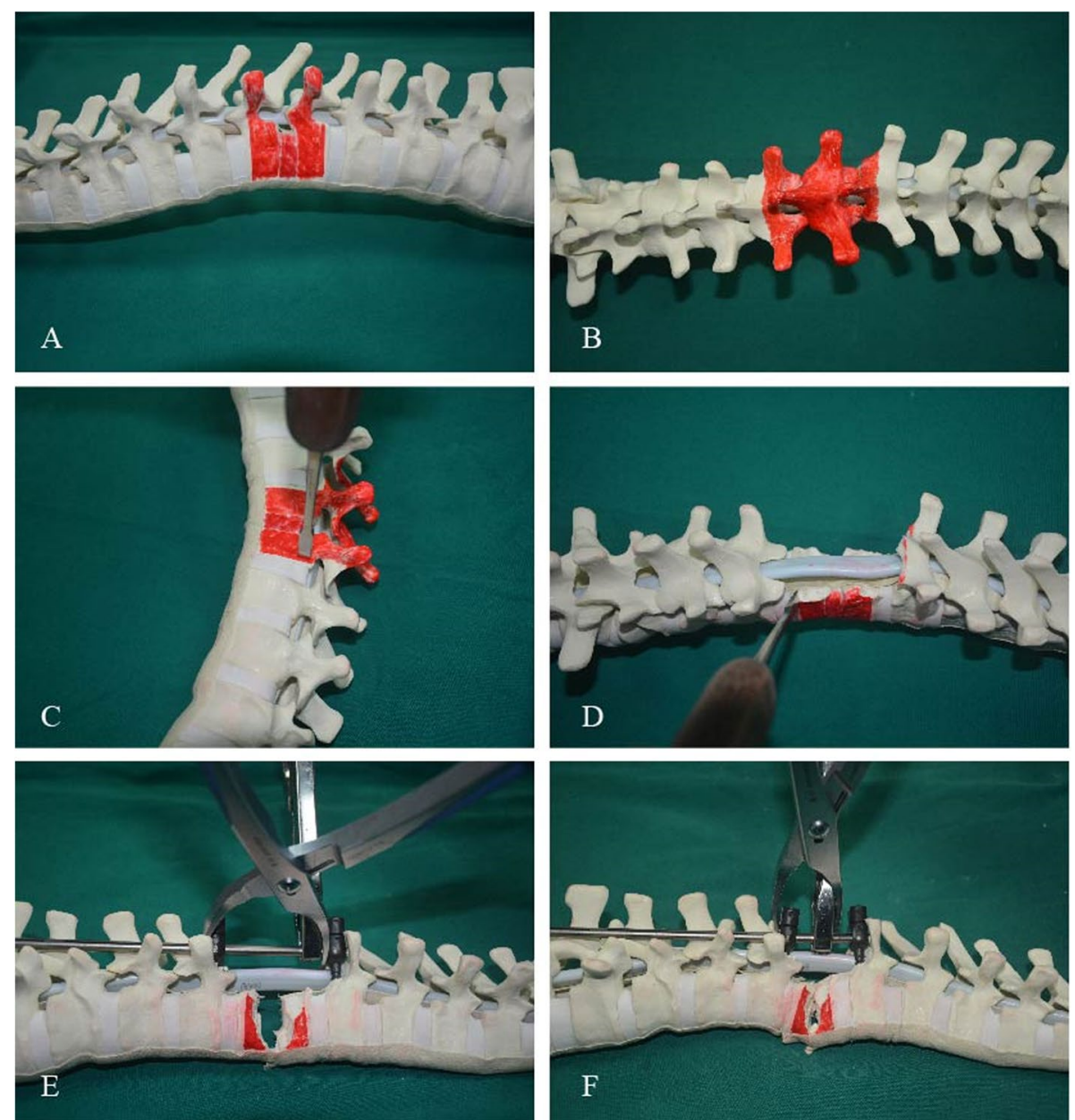

Fig. 2 Simple operative schema of the thoracic parallel endplate osteotomy (PEO) procedure. A, B and C The resection region (the pedicle of the vertebral arch, $4 / 5$ of the posterior vertebra, the bilateral walls of the vertebra and the posterior wall of the vertebra) is marked. DThe temporary stabilizing rod is placed to the concave side to complete spinal canal decompression and PEO is performed. $\mathbf{E}$ and $\mathbf{F}$ Compression over the resected area and shortening of the spine are performed to reduce tension on the spinal cord. The surgeon then bends the rod in situ on the coronal plane or sagittal plane for correction and observes the migration of the dural sac; compression and bending of rods on both the convex and concave sides are undertaken to adjust tension of the spinal cord

\section{PEO grade}

Grade I: For patients with a scoliosis and kyphosis angle less than $80^{\circ}$, we recommended osteotomy that involved a single vertebra by PEO (Fig. 4A). The osteotomy angle can reach $50^{\circ}-60^{\circ}$, and the correction rate can reach $80-85 \%$ by data from the previous cases. Grade II: For patients with a scoliosis and kyphosis angle between $80^{\circ}$ and $100^{\circ}$, we recommended osteotomy that involved a single vertebra and the intervertebral disc by PEO (Fig. 4B). The osteotomy angle can reach $70^{\circ}-85^{\circ}$, and the correction rate can reach 70-85\%. Grade III: For patients with a scoliosis and kyphosis angle between $101^{\circ}$ and $120^{\circ}$, we recommended osteotomy that involved two vertebrae and the intervertebral disc by PEO (Fig. 4C). The osteotomy angle can reach $80^{\circ}-100^{\circ}$, and the correction rate can reach $70-85 \%$. Grade IV: For patients with a scoliosis and kyphosis angle more than $120^{\circ}$, we recommended osteotomy that involved two or more vertebrae and the intervertebral disc by PEO (Fig. 4D). The osteotomy angle can reach $100^{\circ}-120^{\circ}$, and the correction rate can reach $70-75 \%$. According to the severity of spinal cord folds, blood supply, tolerance of spinal cord twists, electrophysiological monitoring or wake-up experiments to determine whether to add the titanium mesh implants for the front support of the vertebral, we had a maximum spinal shortening of $5 \mathrm{~cm}$ (Fig. 5A and B). For some patients with a smaller 


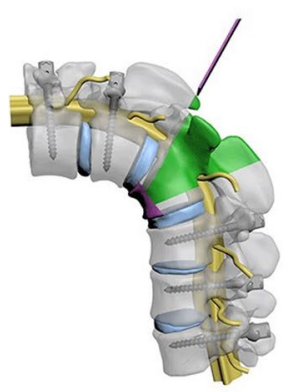

A

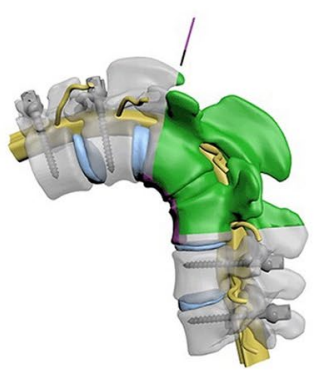

D

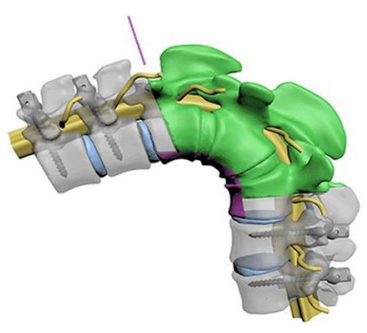

G

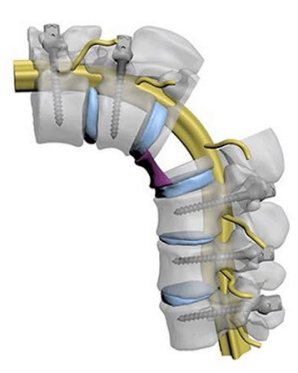

B

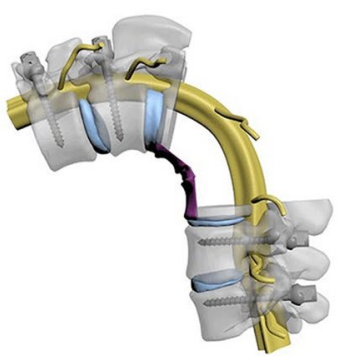

E

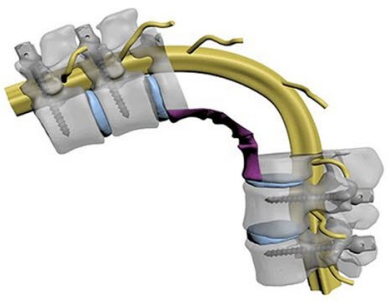

$\mathrm{H}$

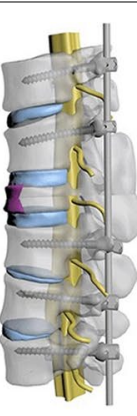

C
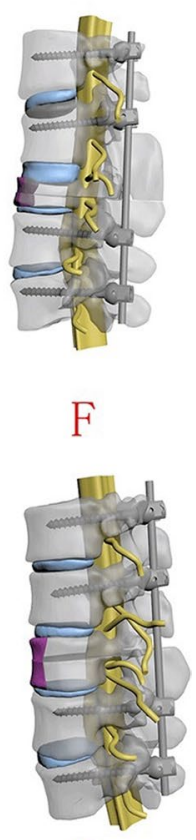

I

Fig. 3 The 3-D digital demonstrations. A, B and C A single vertebral PEO. D, E and F The double-vertebra PEO. G, H and I The three-vertebra PEO

scoliosis and kyphosis angle but have multi-vertebral malformation (butterfly vertebra or other deformities) that need to be removed, a higher grade level of PEO osteotomy was adopted.

\section{Data analysis}

Data were displayed as mean \pm SD unless otherwise indicated. Student's $t$ test was used to evaluate the differences after surgery. Statistical significance was set at a value of $P<0.05$.

\section{Results}

In total, 36 severe rigid spinal deformities patients received a PEO. The 3D model provided accurate diagnostic and better surgical options. The kyphosis and scoliosis correction rates reached $77.4 \pm 14 \%$ and
$72.2 \pm 18.2 \%$, respectively. The median intraoperative estimated blood loss was $1500 \mathrm{~mL}$ and median the operative time was $6.8 \mathrm{~h}$ (Table 1). The median duration of follow up was 32 months (range 24 to 50 months). Table 2 shows SF-36 scores of the patients at baseline, and at 12 months, 18 months and 24 months postoperatively, respectively. The SF-36 scores of physical function, role-physical, bodily pain, general health, vitality, social function, role-emotional and mental health changed from $62 \pm 28,51 \pm 26,49 \pm 29,35 \pm 30,53 \pm 28$, $45 \pm 30,32 \pm 34$ and $54 \pm 18$ at baseline to $81 \pm 16$, $66 \pm 41,72 \pm 40,64 \pm 44,75 \pm 25,71 \pm 46,66 \pm 34$ and $76 \pm 28$ at 12 months postoperatively, $82 \pm 32,67 \pm 42$, $81 \pm 30,71 \pm 41,80 \pm 30,74 \pm 36,68 \pm 35$ and $85 \pm 33$ at 18 months postoperatively, and $86 \pm 21,83 \pm 33$, $88 \pm 26,79 \pm 39,86 \pm 36,86 \pm 48,80 \pm 47$ and $91 \pm 39$ at 

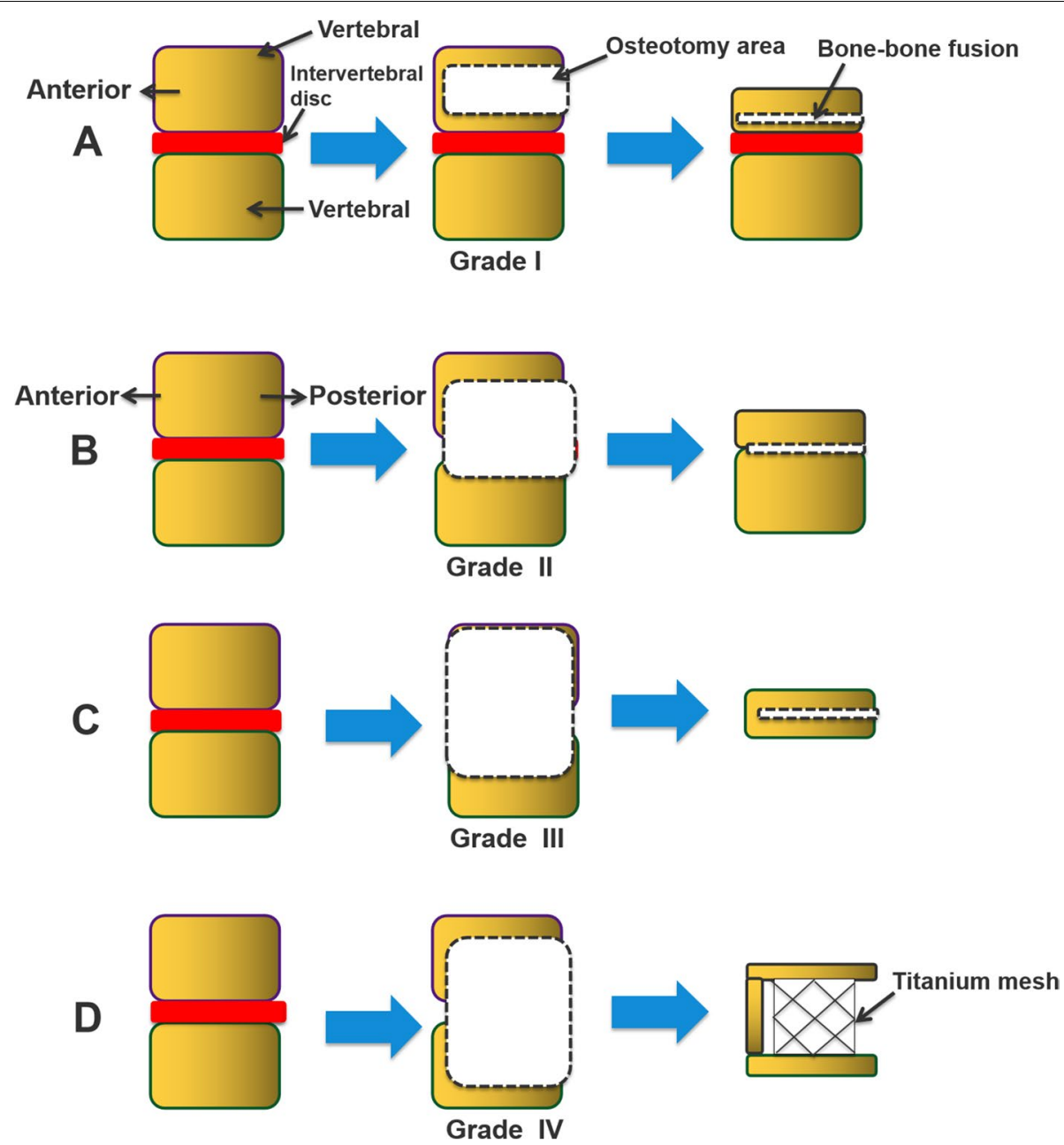

Fig. 4 The PEO osteotomy grade classification. A Grade l: For scoliosis and kyphosis angle less than $80^{\circ}$, PEO with a single vertebra is recommended. B Grade II: For scoliosis and kyphosis $\left(80^{\circ}-100^{\circ}\right)$, PEO with a single vertebra and the intervertebral disc is recommended. C Grade III: For scoliosis and kyphosis $\left(101^{\circ}-120^{\circ}\right)$, PEO with two or more vertebrae and the intervertebral disc is recommended. D Grade IV: For scoliosis and kyphosis angle more than $120^{\circ}$, PEO with two or more vertebrae and the intervertebral disc is recommended. According to the severity of spinal cord folds, blood supply, tolerance of spinal cord twists, electrophysiological monitoring or wake-up experiments are used to determine whether to add titanium mesh implants for the front support of the vertebra

24 months postoperatively, respectively $(P<0.05$, Student's $t$ test), indicating that the quality of life of the patients improved significantly after PEO.

Although the clinical effect of the PEO technique was apparent, complications were unavoidable. L1 nerve root injury occurred in three $(8.3 \%)$ patients, with intraoperative abnormal SEP and MEP wave forms. To further prove that the L1 nerve root was damaged intraoperatively, we performed a lower limb EMG postoperatively. The symptoms of L1 nerve root injury were significantly improved by pharmacotherapy with mannitol and methylprednisolone and nutritional neurotherapy support with monosialotetrahexosylganglioside. Meanwhile, two (5.6\%) cases developed hemothorax, which was effectively repaired without any leakage, and a closed thoracic drainage tube was placed postoperatively. One (2.8\%) patient experienced paralytic ileus which improved after gastric decompression, promoting intestinal motility and symptomatic medical treatment. One $(2.8 \%)$ case developed superficial infection, which healed after thorough debridement. Two (5.6\%) patients experienced distal screw loosening which improved after revision surgery. At the two-year follow up, we did not observe any other complications, such as dura laceration, nonunion/rod breakage and adjacent segment kyphosis (Table 3). At the last follow-up, firm bony fusion was observed in all patients. 


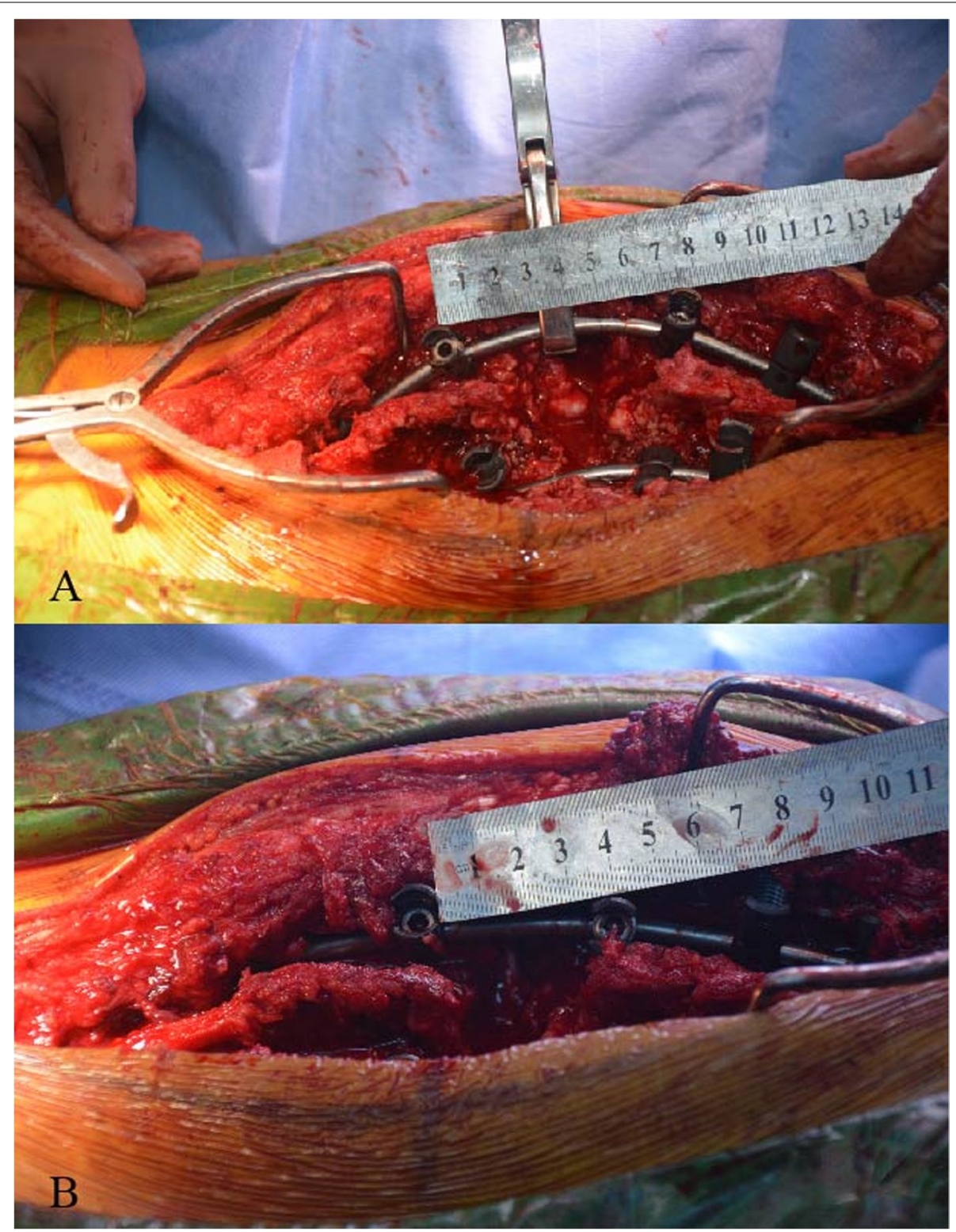

Fig. $5 \mathbf{A}$ and $\mathbf{B}$ Spinal shortening during PEO

\section{Typical case}

\section{PEO grade II}

A 38-year-old woman was diagnosed with idiopathic kyphoscoliosis (Patient No.11). Preoperative reconstructed CT scan and radiographs showed scoliosis $\left(\right.$ Cobb angle $63^{\circ}$ ) and kyphosis (Cobb angle $85^{\circ}$ ) (Fig. 6A and $\mathrm{B}$ ). Postoperative radiographs and reconstructed $\mathrm{CT}$ scan demonstrated the results of PEO with posterior spinal fusion. The scoliotic curve was corrected to $15^{\circ}$ and the kyphotic curve to $25^{\circ}$ (Fig. 6C and Fig. 6D).

\section{PEO grade III}

A 25-year-old woman was diagnosed with congenital kyphoscoliosis (Patient No.3). Preoperative reconstructed $\mathrm{CT}$ and radiographs showed scoliosis (Cobb angle $98^{\circ}$ ) and kyphosis (Cobb angle $112^{\circ}$ ) (Fig. 6E and F). Postoperative radiographs and reconstructed $\mathrm{CT}$ revealed the results of $\mathrm{PEO}$ with posterior spinal fusion: the scoliotic curve was corrected to $18^{\circ}$ and the kyphotic curve to $20^{\circ}$ (Fig. 6G and Fig. $6 \mathrm{H}$ ). 
Table 1 Summarized data of patients

\begin{tabular}{|c|c|c|c|c|c|c|c|c|c|}
\hline $\begin{array}{l}\text { Patient } \\
\text { No. }\end{array}$ & $\begin{array}{l}\text { Age/ } \\
\text { Sex }\end{array}$ & Etiology & $\begin{array}{l}\text { Kyphosis } \\
\text { Cobb } \\
\text { (degrees) } \\
\text { Pre-op } \\
\text { Post-op }\end{array}$ & $\begin{array}{l}\text { Scoliosis } \\
\text { Cobb } \\
\text { (degrees) } \\
\text { Pre-op } \\
\text { Post-op }\end{array}$ & $\begin{array}{l}\text { Osteotomy } \\
\text { segments }\end{array}$ & $\begin{array}{l}\text { Osteotomy } \\
\text { grade }\end{array}$ & $\begin{array}{l}\text { Upper and } \\
\text { lower end } \\
\text { vertebra }\end{array}$ & Bleeding $(\mathrm{mL})$ & $\begin{array}{l}\text { Operative time } \\
\text { (hours) }\end{array}$ \\
\hline 1 & $33 / F$ & Idiopathic & 8512 & 6715 & $\mathrm{~T} 11 / \mathrm{T} 12$ & III & T8-L4 & 1800 & 5.6 \\
\hline 2 & $22 / \mathrm{M}$ & Idiopathic & 9025 & 13040 & $\mathrm{~T} 12 / \mathrm{L} 1$ & IV & T5-L5 & 3000 & 11 \\
\hline 3 & $25 / F$ & Congenital & 11220 & 9818 & $\mathrm{~T} 12 / \mathrm{L} 1$ & III & T8-L5 & 1500 & 5.8 \\
\hline 4 & $8 / \mathrm{M}$ & Tuberculosis & 9816 & - & $\mathrm{T} 10 / \mathrm{T} 11 / \mathrm{T} 12$ & IV & T5-L4 & 1000 & 6 \\
\hline 5 & $21 / M$ & Idiopathic & 10232 & 11835 & L1/L2 & III & T8-S1 & 3000 & 5.5 \\
\hline 6 & $10 / F$ & Congenital & 9022 & 7816 & $\mathrm{~T} 11 / \mathrm{T} 12$ & III & T6-L3 & 1500 & 5 \\
\hline 7 & $15 / \mathrm{M}$ & Idiopathic & 10824 & 13135 & T9/T11/T12 & IV & T4-L5 & 2600 & 9 \\
\hline 8 & $24 / F$ & Congenital & 10015 & 8514 & $\mathrm{~T} 12 / \mathrm{L} 1$ & III & T9-L5 & 1800 & 6.3 \\
\hline 9 & $16 / \mathrm{M}$ & Congenital & 14844 & - & $\mathrm{T} 12 / \mathrm{L} 1$ & IV & T5-L4 & 2000 & 10 \\
\hline 10 & $20 / F$ & Congenital & 16646 & - & $\mathrm{T} 10 / \mathrm{T} 11 / \mathrm{T} 12$ & IV & T5-L5 & 1700 & 7 \\
\hline 11 & $38 / F$ & Idiopathic & 8525 & 6315 & L1 & $\|$ & T9-L4 & 2500 & 5.5 \\
\hline 12 & $32 / M$ & Congenital & 10020 & 5417 & $\mathrm{~T} 12$ & $\|$ & T8-L4 & 1000 & 7 \\
\hline 13 & $31 / M$ & Idiopathic & - & 9129 & T8 & $\|$ & T4-L4 & 800 & 10.2 \\
\hline 14 & 19/M & Idiopathic & - & 9725 & $\mathrm{~T} 10$ & $\|$ & T5-L3 & 3500 & 10.4 \\
\hline 15 & $22 / F$ & Idiopathic & - & 10528 & L2 & $\|$ & T12-L3 & 2000 & 13.4 \\
\hline 16 & $14 / \mathrm{M}$ & Idiopathic & - & 9124 & T9 & $\|$ & T5-L1 & 1400 & 5.8 \\
\hline 17 & $12 / \mathrm{M}$ & Idiopathic & - & 9025 & $\mathrm{~T} 10 / \mathrm{T} 11$ & III & T4-L4 & 800 & 7 \\
\hline 18 & $19 / M$ & Idiopathic & - & 10024 & $\mathrm{T7}$ & $\|$ & T5-L5 & 3000 & 9.3 \\
\hline 19 & $19 / F$ & Idiopathic & - & 10727 & $\mathrm{~T} 12 / \mathrm{L} 1$ & III & T5-L5 & 1500 & 6.8 \\
\hline 20 & $42 / F$ & Ankylosing & 9019 & - & L3 & $\|$ & T11-L5 & 1300 & 5.9 \\
\hline 21 & $25 / \mathrm{M}$ & Ankylosing & 8515 & - & L2 & $\|$ & T8-L5 & 1500 & 6.3 \\
\hline 22 & $43 / F$ & Ankylosing & 8510 & - & L3 & $\|$ & T9-L5 & 1800 & 6.3 \\
\hline 23 & $55 / F$ & Congenital & 8212 & - & L3 & $\|$ & T7-L5 & 1500 & 5.3 \\
\hline 24 & $42 / \mathrm{M}$ & Ankylosing & 8518 & - & L2 & $\|$ & T9-L5 & 1500 & 7 \\
\hline 25 & $17 / F$ & Idiopathic & 9920 & 9721 & $\mathrm{~T} 7 / \mathrm{L} 2$ & III & T3-L5 & 1800 & 10.4 \\
\hline 26 & $25 / \mathrm{M}$ & Idiopathic & 10828 & 13140 & $\mathrm{~T} 7 / \mathrm{T} 8$ & IV & T8-L5 & 2600 & 8.8 \\
\hline 27 & $16 / F$ & Idiopathic & - & 10537 & T5/T6 & III & T3-L5 & 2000 & 9.3 \\
\hline 28 & $14 / \mathrm{M}$ & Congenital & 10323 & - & T9/Т10 & III & T5-L1 & 2100 & 6.8 \\
\hline 29 & $38 / F$ & Ankylosing & 9018 & - & L2 & $\|$ & T9-L4 & 1500 & 6 \\
\hline 30 & $45 / \mathrm{M}$ & Ankylosing & 8515 & - & L2 & $\|$ & T10-L5 & 1000 & 6.8 \\
\hline 31 & $8 / \mathrm{M}$ & Congenita & 4615 & 10335 & T9 & $\|$ & T7-L2 & 600 & 4.8 \\
\hline 32 & $11 / F$ & Congenita & - & 8016 & $\mathrm{~T} 4 / \mathrm{T} 5$ & III & C5-T9 & 1000 & 6.5 \\
\hline 33 & $14 / \mathrm{M}$ & Idiopathic & - & 10247 & Т8/T9 & III & T4-L2 & 1300 & 8.8 \\
\hline 34 & $13 / F$ & Congenita & 9225 & 10735 & T9/T10 & III & T5-L5 & 1500 & 8.8 \\
\hline 35 & $38 / F$ & Idiopathic & 8230 & 6317 & $\mathrm{~T} 10$ & $\|$ & T9-L4 & 2500 & 5.5 \\
\hline 36 & $15 / \mathrm{M}$ & Idiopathic & - & 14760 & Т7/T8 & IV & T4-L3 & 3500 & 9 \\
\hline
\end{tabular}

\section{PEO grade IV}

A 20-year-old woman with congenital kyphosis (Patient No.10). Preoperative photograph demonstrating reconstructed CT and radiographs showing Kyphosis Cobb $\left(166^{\circ}\right)$ planes (Fig. 6I and J). Radiographs and reconstructed CT demonstrating the results of PEO with posterior spinal fusion and the titanium mesh implants for the front support of the vertebral, the kyphotic curve was corrected to $46^{\circ}$ (Fig. $6 \mathrm{~K}$ and Fig. 6L).

\section{Discussion}

Spinal deformity is a 3D deformity. Decompensation in the coronal and sagittal planes leads to specific complaints including pain, progression of deformity, 
Table 2 SF-36 scores before surgery and at 12, 18 and 24 months postoperatively. $(n=36)$

\begin{tabular}{ccccccccc}
\hline Time points & Physical Function & Role-Physical & Bodily Pain & General Health & Vitality & $\begin{array}{l}\text { Social } \\
\text { Function }\end{array}$ & Role-Emotional & Mental Health \\
\hline $\begin{array}{l}\text { Before surgery } \\
\text { After surgery }\end{array}$ & $62 \pm 28$ & $51 \pm 26$ & $49 \pm 29$ & $35 \pm 30$ & $53 \pm 28$ & $45 \pm 30$ & $32 \pm 34$ & $54 \pm 18$ \\
12 months & $81 \pm 16$ & $66 \pm 41$ & $72 \pm 40$ & $64 \pm 44$ & $75 \pm 25$ & $71 \pm 46$ & $66 \pm 34$ & $76 \pm 28$ \\
18 months & $82 \pm 32$ & $67 \pm 42$ & $81 \pm 30$ & $71 \pm 41$ & $80 \pm 30$ & $74 \pm 36$ & $68 \pm 35$ & $85 \pm 33$ \\
24 months & $86 \pm 21$ & $83 \pm 33$ & $88 \pm 26$ & $79 \pm 39$ & $86 \pm 36$ & $86 \pm 48$ & $80 \pm 47$ & $91 \pm 39$ \\
\hline
\end{tabular}

Table 3 Complications in the study patients

\begin{tabular}{ll}
\hline Complication & Patients $(\boldsymbol{n}=\mathbf{3 6})$ \\
\hline Dura laceration & 0 \\
L1 nerve root injury & $3(8.3 \%)$ \\
Paralytic ileus & $1(2.8 \%)$ \\
Hemothorax & $2(5.6 \%)$ \\
Superficial infection & $1(2.8 \%)$ \\
Nonunion/rod broken & 0 \\
Distal screw loosening & $2(5.6 \%)$ \\
Adjacent segment kyphosis & 0
\end{tabular}

deranged trunk balance, cardiopulmonary compromise, interference with daily living activities, and, in some cases, neurologic deficits [19]. The surgical objective for severe (Cobb angle $>80^{\circ}$ ) kyphosis and rigid spinal kyphoscoliosis deformities is decompression of neurological elements and correction of the deformities, which have always been a great challenge for spine specialists [20]. The surgical treatment is highly demanding and risky for both the surgeon and the patient [21]. In severe rigid spinal deformities, conventional correction methods, including posterior instrumentation and fusion or combinations of anterior release and posterior instrumentation and fusion, are usually unsatisfactory [22, 23]. Therefore, a more aggressive approach is necessary.

Posterior osteotomies allow correction through a hinge action. For severe rigid spinal deformities, the resection of apical region of the deformity is often performed by the PVCR procedure [24]. However, the hinge of the PVCR is the spinal cord, with the potential for various spinal cord-related neurological complications. PEO also differs from conventional vertebral column resection and PVCR in the usage of the spinal hinge, intraoperative deformity correction, and spinal reconstruction. However, the pedicle of the vertebral arch is taken as the main anatomic landmark of most surgical osteotomies. As for severe rigid spinal deformities, osteotomy is just inside the pedicle, which limits the range of osteotomy and leaves the orthopaedic surgeon unsatisfied. Those osteotomies are mostly PSO, VCD, eggshell and so on. PEO, which has been described in our previously published paper [15], includes the pedicle of the vertebral arch, 4/5 of the posterior vertebra, the bilateral walls of the vertebra and the posterior wall of the vertebra $(5 \mathrm{~mm}$ to the endplate), which does not require thorough pedicular osteotomy like PSO and resection of the intervertebral disc above and below the osteotomy site like VCR. Moreover, the endplate as a mark in PEO is easy to identify which has a large operating space, and is especially suitable for pedicle deformity or agenesis which is unrecognizable, which is easier to operate for orthopedic surgeons. With bone-bone fusion, we can achieve a higher spinal fusion rate and better spine stability in order to reduce the risk of rod breakage. For spine deformity, PSO and VCR are classic techniques and can achieve satisfactory results. Meanwhile, the PEO technique provides a new alternative treatment for spinal deformities, with a median intraoperative estimated blood loss of $1500 \mathrm{~mL}$ and a median operative time of $6.8 \mathrm{~h}$. The osteotomy angle can reach $110^{\circ}-140^{\circ}$, basically satisfying any angle requirements for correction of spinal deformity. The kyphosis and scoliosis average correction rates reached 77.4 and $72.2 \%$, respectively, which are better than the traditional correction rate of 55-60\% [25].

There is no permanent spinal cord injury in our series. The risk of spinal cord-related neurological complications is always emphasized in the literature concerning deformity correction. Potential neurological abnormalities should be noticed before corrective surgery. In our series of patients, $3 / 36$ cases with very severe kyphoscoliosis had intraoperative neurological abnormalities. It was likely that the correction procedure caused spinal cord breakdown, thus increasing the tension on the spinal cord and reducing blood supply, accompanied by pathological changes. The patient presented with neurological symptoms intraoperatively, but operative exploration excluded mechanical compression, so the patient was treated with methylprednisolone and recovered completely within 2 weeks. Despite a different kind of anomaly, the corrective surgeries in these 3 patients achieved good results. We believe that a careful 


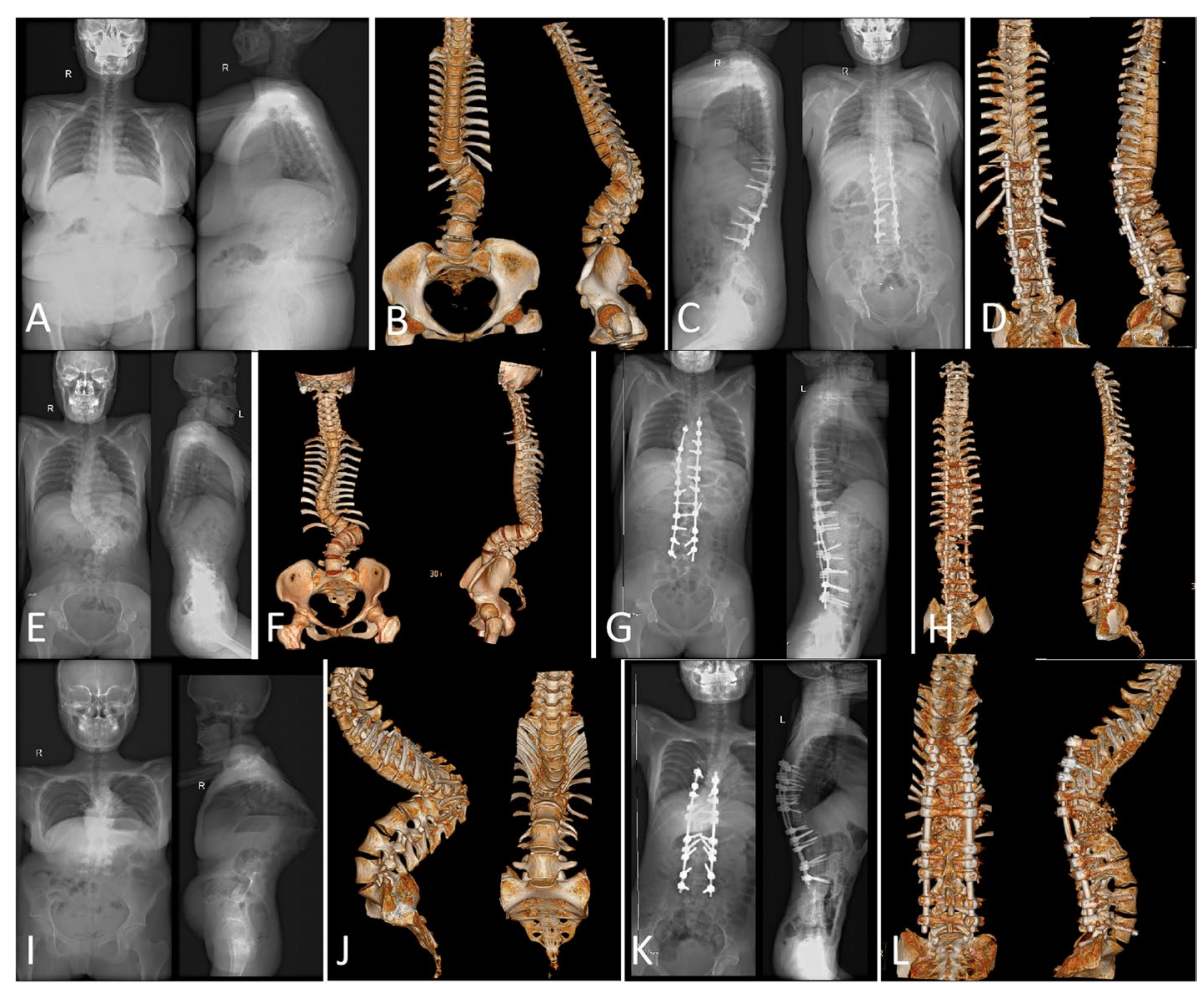

Fig. 6 A 38-year-old woman with idiopathic kyphoscoliosis who received grade II PEO. A and B Preoperative reconstructed CT and radiographs showing scoliosis, Cobb $\left(63^{\circ}\right)$ and kyphosis, Cobb $\left(85^{\circ}\right)$. C and $\mathbf{D}$ Radiographs and reconstructed $\mathrm{CT}$ demonstrating the results of PEO with posterior spinal fusion; the scoliotic curve was corrected to $15^{\circ}$ and the kyphotic curve to $25^{\circ}$. A 25 -year-old woman with congenital kyphoscoliosis who underwent grade III PEO. E and F Preoperative reconstructed CT and radiographs showing scoliosis, Cobb $\left(98^{\circ}\right)$ and kyphosis, Cobb $\left(112^{\circ}\right)$. G and H Radiographs and reconstructed CT demonstrating the results of PEO with posterior spinal fusion: the scoliotic curve was corrected to $18^{\circ}$ and the kyphotic curve to $20^{\circ}$. A 20 -year-old woman with congenital kyphosis who received grade IV PEO. I and $\mathbf{J}$ Preoperative reconstructed CT and radiographs showing kyphosis Cobb, $\left(166^{\circ}\right)$. $\mathbf{K}$ and $\mathbf{L}$ Radiographs and reconstructed CT demonstrating the results of PEO with posterior spinal fusion and the titanium mesh implants for the front support of the vertebra; the kyphotic curve was corrected to $46^{\circ}$

manipulation and continuous monitoring of spinal cord function are crucial for maintaining the integrity of neurological functions. In addition, severe deformity corrections that lead to spinal cord shortening can effectively relieve the over-tension of a tethered cord. In some cases of spinal deformity with multi-level vertebral loss, the spinal cord is in a state of high tension and has poor blood supply, minor traction during surgery can cause acute and severe spinal cord injury, leading to complete or incomplete paraplegia, these cases are considered to be high risk spinal cord cases. Though there is no definitive evidence as to what caused the neurologic compromise, we believe that it might be related to the blood supply of the thoracic cord and preoperative functional status of the spinal cord, which tolerates little additional compromise. At the two year follow-up after surgery, it is obvious from the SF-36 scores that all patients achieved better clinical results and with no other complications.

\section{Conclusions}

We demonstrate that PEO is effective and relatively safe in correcting severe rigid spinal deformity. The PEO technique creates a hinge for spinal correction and spinal cord tension adjustment, and the correction can be performed under direct inspection and by observation and palpation of the tension in the spinal cord through the hinge. We propose for the first time the grade classification of PEO osteotomy. At the two-year follow-up after surgery, it is obvious from the SF-36 scores that all patients achieved better clinical results.

\section{Abbreviations}

PEO: Parallel endplate osteotomy; SEP: Somatosensory-evoked potential; MEP: Motor-evoked potential; EMG: Electromyography; SPO: Smith Peterson osteotomies; PVCR: Posterior vertebral column resection; VCD: Vibrational circular dichroism; PSO: Pedicular subtraction osteotomy; VCR: Vertebral column resection.

\section{Acknowledgements}

Not applicable. 


\section{Authors' contributions}

$H L$ and SXD participated in drafting the manuscript, in designing the protocol and provides the original idea of the work. PX, participated in drafting the manuscript and in designing the protocol. GZZ participated in revising the manuscript critically and in designing statistical analysis. XDL participated in revising the manuscript critically with reference to the methods to evaluate variables. HGM and NDL, participated in revising the manuscript critically with reference to the treatment technics to be studied. All authors have read and approved the final manuscript and agreed to be accountable for all aspects of the work.

\section{Funding}

The study was not supported by any funds.

\section{Availability of data and materials}

All data generated or analysed during this study are included in this published article and its supplementary information files.

\section{Declarations}

\section{Ethics approval and consent to participate}

The study protocol has been approved by the Clinical Research Ethics Committee of the Shenzhen University on May 10th, 2016 and has been registered. All the participants and also from parents or legal guardians of minor participants in the manuscript signed an written informed consent. All procedures were performed in accordance with relevant guidelines' in the manuscript.

\section{Consent for publication}

Written consent was provided for images of the patients and techniques, clinical details and identifying information such as age, profession and gender to be included and published.

\section{Competing interests}

The authors declare that they have no competing interests.

Received: 5 April 2021 Accepted: 16 November 2021

Published online: 03 December 2021

\section{References}

1. Xie J, Wang Y, Zhao Z, et al. Posterior vertebral column resection for correction of rigid spinal deformity curves greater than 100 degrees. J Neurosurg Spine. 2012;17:540-51.

2. Dobbs MB, Lenke LG, Kim YJ, et al. Anterior/posterior spinal instrumentation versus posterior instrumentation alone for the treatment of adolescent idiopathic scoliotic curves more than 90 degrees. Spine. 2006:31:2386-91.

3. Newton PO, Perry A, Bastrom TP, et al. Predictors of change in postoperative pulmonary function in adolescent idiopathic scoliosis: a prospective study of 254 patients. Spine. 2007;32:1875-82.

4. Steinmetz MP, Rajpal S, Trost G. Segmental spinal instrumentation in the management of scoliosis. Neurosurgery. 2008:63:131-8.

5. Bridwell $\mathrm{KH}$, Lewis SJ, Rinella A, et al. Pedicle subtraction osteotomy for the treatment of fixed sagittal imbalance. Surgical technique. J Bone Joint Surg Am. 2004;86:44-50.

6. Hankinson TC, Klimo P, Feldstein NA, et al. Chiari malformations, syringohydromyelia and scoliosis. Neurosurg Clin N Am. 2007;18:549-68.

7. Kawahara N, Tomita K, Baba H, et al. Closing-opening wedge osteotomy to correct angular kyphotic deformity by a single posterior approach. Spine. 2001;26:391-402

8. Smith-Petersen MN, Larson CB, Aufranc OE. Osteotomy of the spine for correction of flexion deformity in rheumatoid arthritis. Clin Orthop Relat Res. 1969:66:6-9.

9. Suh SW, Modi HN, Yang J, et al. Posterior multilevel vertebral osteotomy for correction of severe and rigid neuromuscular scoliosis: a preliminary study. Spine. 2009;34:1315-20.

10. Bridwell KH. Decision making regarding Smith-Petersen vs. pedicle subtraction osteotomy vs. vertebral column resection for spinal deformity. Spine. 2006;31:S171-8.
11. Wang Y, Lenke LG. Vertebral column decancellation for the management of sharp angular spinal deformity. Eur Spine J. 2011;20:1703-10.

12. Smith JS, Sansur CA, Donaldson WF, et al. Short-term morbidity and mortality associated with correction of thoracolumbar fixed sagittal plane deformity: a report from the Scoliosis Research Society morbidity and mortality committee. Spine. 2011;36:958-64.

13. Lenke LG, Newton PO, Sucato DJ, et al. Complications after 147 consecutive vertebral column resections for severe pediatric spinal deformity: a multicenter analysis. Spine. 2013;38:119-32.

14. Hamzaoglu A, Alanay A, Ozturk C, et al. Posterior vertebral column resection in severe spinal deformities: a total of 102 cases. Spine. 2011;36:E340-4.

15. Liao H, Miao HG, Xie P, Wang YY, Li ND, Zheng GZ, et al. Protection of L1 nerve roots by pre-relieve tension in parallel endplate osteotomy for severe rigid thoracolumbar spine deformity. BMC Musculoskelet Disord. 2020;21:306-17.

16. Xie J, Wang Y, Zhao Z, et al. One-stage and posterior approach for correction of moderate to severe scoliosis in adolescents associated with Chiari I malformation: is a prior suboccipital decompression always necessary? Eur Spine. 2011;20:1106-13.

17. Kawahara N, Tomita K, Kobayashi T, et al. Influence of acute shortening on the spinal cord: an experimental study. Spine. 2005;30:613-20.

18. Sar C, Eralp L. Three-stage surgery in the management of severe rigid angular kyphosis. Eur Spine. 2002;11:107-14.

19. Bradford DS, Tribus CB. Vertebral column resection for the treatment of rigid coronal decompensation. Spine. 1997;22:1590-9.

20. Bohinski RJ, Rhines LD. Principles and techniques of en bloc vertebrectomy for bone tumors of the thoracolumbar spine: an overview. Neurosurg Focus. 2003;15:E7-10.

21. Liu Y, Li G, Dong T, et al. One-stage partial vertebrectomy, titanium mesh implantation and pedicle screw fixation in the treatment of thoracolumbar burst fractures through a posterior approach. Clinics. 2014;69:804-8.

22. Leatherman KD, Dickson RA. Two-stage corrective surgery for congenital deformities of the spine. J Bone Joint Surg Br. 1979;61:324-8.

23. Bradford DS, Boachie-Adjei O. One-stage anterior and posterior hemivertebral resection and arthrodesis for congenital scoliosis. J Bone Joint Surg Am. 1990;72:536-40.

24. Suk SI, Kim JH, Kim WJ. Posterior vertebral column resection for severe spinal deformities. Spine. 2002;27:2374-82

25. Cui G, Wang Y, Kao TH, et al. Application of intraoperative computed tomography with or without navigation system in surgical correction of spinal deformity: a preliminary result of 59 consecutive human cases. Spine. 2012;37:891-900.

\section{Publisher's Note}

Springer Nature remains neutral with regard to jurisdictional claims in published maps and institutional affiliations.

Ready to submit your research? Choose BMC and benefit from

- fast, convenient online submission

- thorough peer review by experienced researchers in your field

- rapid publication on acceptance

- support for research data, including large and complex data types

- gold Open Access which fosters wider collaboration and increased citations

- maximum visibility for your research: over 100M website views per year

At BMC, research is always in progress.

Learn more biomedcentral.com/submissions 